\title{
Securing Access to Hemodialysis Care After Typhoon Hagibis in Fukushima
}

\author{
Yoshitaka Nishikawa, MD; Sho Fujioka, MD; Yosuke Tachiya, MD; Tomohiro Morita, MD; \\ Masaharu Tsubokura, MD; Akihiko Ozaki, MD; Toyoaki Sawano, MD; Masami Ogawa, MD; \\ Ryuzaburo Shineha, MD
}

$\mathrm{M}$ aintaining health-care access after major disasters is imperative. While disaster support can be deployed rapidly, ${ }^{1}$ on-site staff must begin responding before their arrival and continue working for the long term. Thus, their actions are vital to ensuring health-care access for affected populations. Notably, continuing hemodialysis is a main concern. However, how on-site hospital staff can provide support after disasters remains little studied, particularly with regard to hemodialysis.

On October 12, 2019, Typhoon Hagibis struck Japan, killing more than 80 people (Figure 1). Soma Central Hospital (Soma, Fukushima Prefecture) is located 40 $\mathrm{km}$ north of the Fukushima Daiichi nuclear power plant. At Soma Central Hospital, 70 patients regularly receive hemodialysis, 30-40 patients per day, which requires 18 tons of water daily. After the typhoon, the hospital was hit by floods. Despite damage to some outdoor facilities, the patients, staff, and dialysis equipment were maintained.., the destruction of the water supply system prevented normal water delivery.

The municipal government sent water trucks to the affected health-care facilities on October 13, and clean water was accessible from the local public water supplier (Figure 2). The hospital director decided to keep the patients in the hospital and continue hemodialysis using this water supply. By the evening of October 13, six workers had learned how to use the water trucks, going for clean water nine times each day, with the rest of the staff covering in-hospital work, exhibiting a strong sense of responsibility to preserve life. This way, hemodialysis was successfully continued; on October 16, a disaster support team arrived and took over the water supply, allowing hospital staff to return to their usual work. From October 19, a clean water supply has gradually recovered. During this period, no hemodialysis patients suffered any adverse event.

This report suggests that on-site hospital staff can maintain access to hemodialysis care even after disasters, when the damage can be evaluated and managed. In the reported case, alternative water sources were

\section{FIGURE}
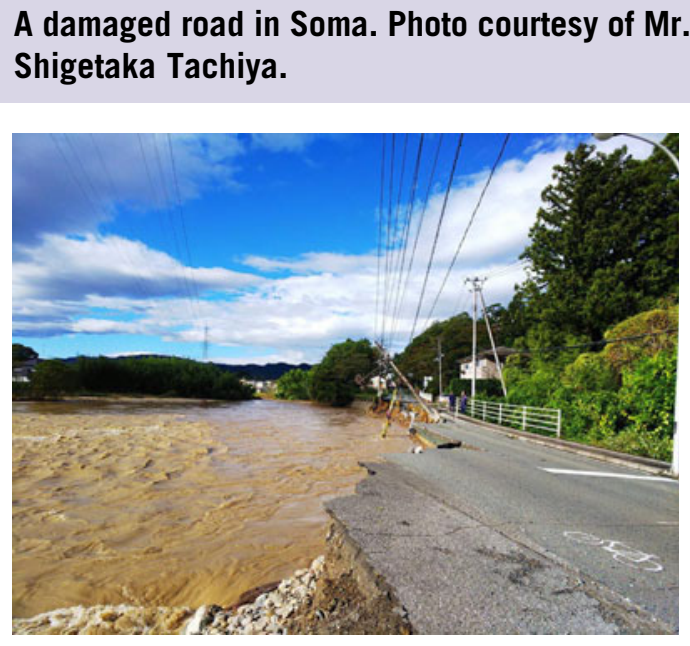

secured through the efforts of on-site staff. During the nuclear disaster at Fukushima, hemodialysis patients were transferred to other facilities because water shortages, blackouts, and the lack of staff impeded hospital work.,3 It would be important for on-site staff to evaluate the extent of damage to hemodialysis care capabilities after a major disaster and compensate for it if possible.

Disaster awareness and resilience allowed the staff to ensure access to hemodialysis. ${ }^{4,5}$ The staff responded in a timely manner, quickly learning how to use water trucks. At the hospital, disaster preparedness training and drills (evacuation drills, fire drills, etc.) have been performed twice a year for quite some time. Furthermore, the recent experience of the Fukushima nuclear disaster may have prompted a sense of responsibility during crises. In addition, Soma City highlighted the importance of hemodialysis care in its disaster prevention planning, as visible from their efforts to provide water trucks to affected health-care facilities. In this respect, it can be said that a close communication between hospitals and a local government in usual conditions contributed to an early success of the disaster response. This case shows the importance of the flexible response of on-site staff to 
FIGURE 2

A water truck supplying water. Photo courtesy of Mr. Shigetaka Tachiya.

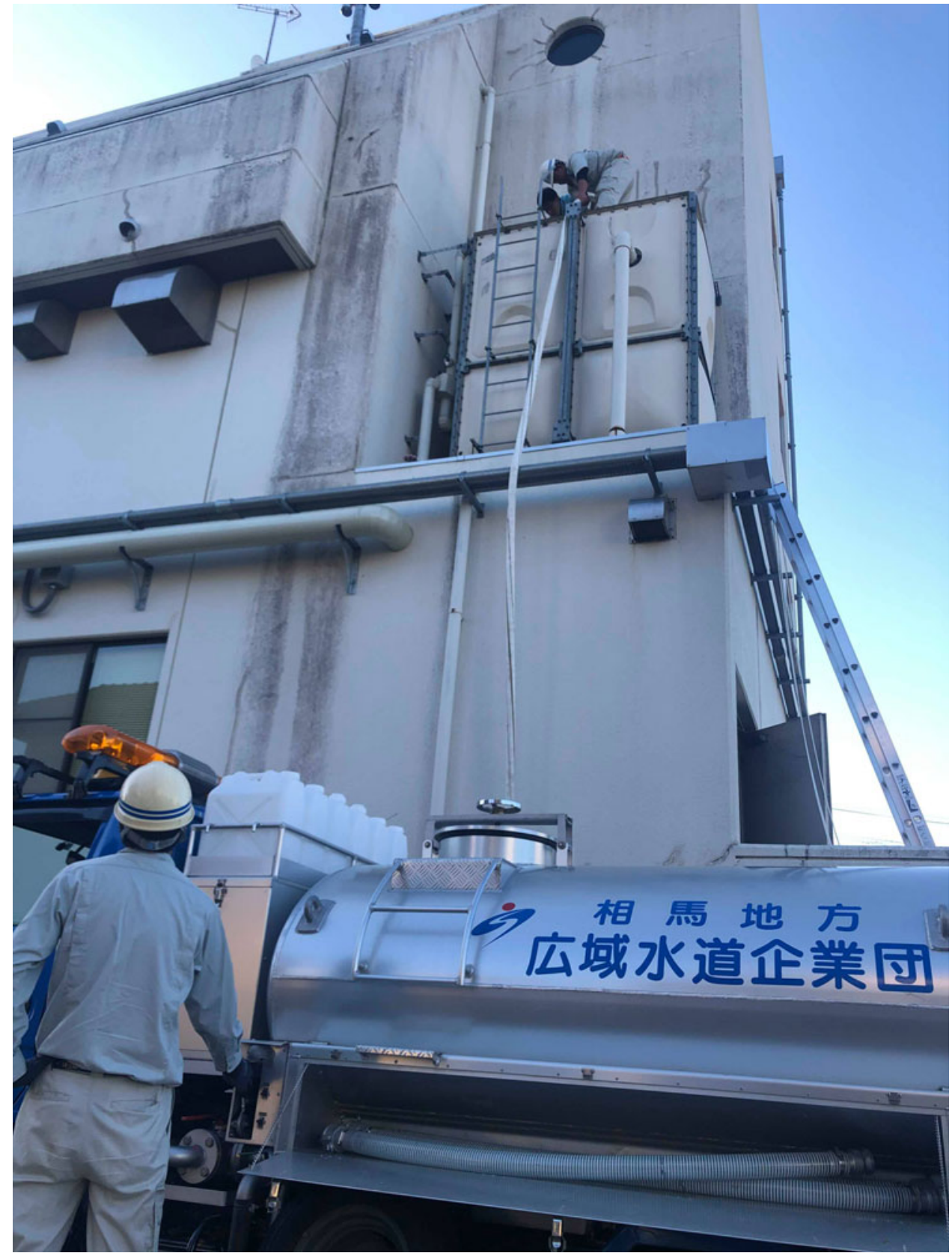

a disaster, together with disaster training and checking equipment and necessities on a daily basis.

\section{About the Authors}

Department of Internal Medicine, Soma Central Hospital, Soma, Fukushima, Japan (Drs Nishikawa, Fujioka, Tachiya, Morita, Tsubokura, Ogawa, Shineha); Department of Health Informatics, Kyoto University School of Public Health, Kyoto, Japan (Dr Nishikawa); Japan Society for the Promotion of Science,
Tokyo, Japan (Dr Nishikawa); Department of Public Health, Fukushima Medical University School of Medicine, Fukushima, Japan (Drs Tsubokura, Sawano); Department of Breast Surgery, Jyoban Hospital of Tokiwa Foundation, Iwaki, Fukushima, Japan (Dr Ozaki); Department of Surgery, Sendai City Medical Center, Sendai Open Hospital, Sendai, Miyagi, Japan (Dr Sawano).

Correspondence and reprint requests to Yoshitaka Nishikawa, Department of Internal Medicine, Soma Central Hospital, 3-5-8, Okinouchi, Soma city, Fukushima, 976-0016, Japan; (e-mail: ynishikawa-tky@umin.ac.jp). 


\section{Acknowledgments}

The authors express their sincere gratitude to the staff of Soma Central Hospital. The authors thank Enago (http://www.enago.jp) and Kana Nishikawa (Kyoto University) for English language review.

\section{REFERENCES}

1. Anan H, Akasaka O, Kondo H, et al. Experience from the Great East Japan Earthquake response as the basis for revising the Japanese Disaster Medical Assistance Team (DMAT) training program. Disaster Med Public Health Prep. 2014;8:477-484.
2. Tsubokura M, Horie S, Komatsu H, et al. The impact of the Great Tohoku Earthquake on the dialysis practice in the disaster-stricken area. Hemodial Int. 2012;16:320-321.

3. Nishikawa Y, Ozawa Y, Tsubokura M, et al. Long-term vulnerability of access to hemodialysis facilities in repopulated areas after the Fukushima Nuclear Disaster: a case report. Oxford Med Case Reports. 2018;7: 228-230.

4. Zhong S, Clark M, Hou XY, et al. Development of hospital disaster resilience: conceptual framework and potential measurement. Emerg Med J. 2014;31:930-938.

5. Cristian B. Hospital Resilience: A Recent Concept in Disaster Preparedness. J Crit Care Med. 2018;4:81-82. 